\title{
ANALISIS PENGARUH FINANCIAL LITERACY TERHADAP MATERIALISME DAN PERILAKU MEMBELANJAKAN UANG (STUDI PADA TARUNA POLITEKNIK ILMU PELAYARAN (PIP) SEMARANG)
}

\author{
Desi Aryani \\ Asisten Dosen PIP Semarang
}

\begin{abstract}
ABSTRAK
Penelitian mengenai pembelian kompulsif merupakan tema yang masih menarik untuk diteliti karena masih adanya perbedaan hasil-hasil penelitian terdahulu (research gap) mengenai faktor-faktor yang mempengaruhi. Mengacu pada temuan mengenai hasil-hasil penelitian terdahulu mendorong peneliti untuk merumuskan pertanyaan penelitian mengenai "Faktor-faktor apa saja yang mempengaruhi perilaku pembelian kompulsif?".

Model penelitian yang dikembangkan dalam studi ini meliputi tiga variabel penelitian, yaitu financial literacy, materialisme dan perilaku pembelian kompulsif. Studi ini dilakukan kepada 160 Taruna Tingkat III Politeknik Ilmu Pelayaran (PIP) Semarang melalui wawancara dengan menggunakan kuesioner. Data yang diperoleh, dianalisis dengan menggunakan Structural Equation Modeling (SEM).

Hasil pengujian statistik menunjukkan bahwa hanya financial literacy yang secara statistik terbukti berpengaruh terhadap materialisme. Sedangkan materialisme dan financial literacy tidak terbukti memiliki pengaruh signifikan terhadap perilaku pembelian kompulsif.
\end{abstract}

\section{Kata kunci: financial literacy, materialisme, perilaku pembelian kompulsif}

\section{PENDAHULUAN}

Perilaku konsumtif yang dilakukan oleh remaja ataupun orang dewasa pada saat ini merupakan suatu realita yang ada. Menurut Afrizal (2012), gaya hidup konsumtif mendorong seseorang untuk menginginkan sesuatu secara instan dan cepat. Konsumerisme tanpa disadari sudah menjadi budaya dan menjurus menjadi penyakit sosial yang berpotensi menciptakan masyarakat individualis dan materialistis bahkan mengarah ke hedonisme. Hal ini ditandai dengan adanya sekelompok masyarakat yang aktif mengkonsumsi produk-produk mewah sebagai sebuah prestige dan kehormatan sekedar sebagai pemenuhan hasrat (Imawati dkk, 2013).

Lebih lanjut Imawati, dkk (2013) menyatakan bahwa perilaku konsumtif dapat terus mengakar di dalam gaya hidup remaja dan jika tidak dikendalikan dalam perkembangannya mereka akan menjadi orang-orang dewasa dengan gaya hidup konsumtif. Gaya hidup konsumtif ini harus selalu didukung oleh kekuatan finansial yang memadai. Masalah lebih besar terjadi apabila pencapaian tingkat finansial itu dilakukan dengan segala macam cara yang tidak sehat, mulai dari pola bekerja yang berlebihan sampai menggunakan cara instan seperti korupsi.

Penelitian mengenai financial literacy masih menarik untuk diteliti karena masih adanya perbedaan hasil-hasil penelitian terdahulu (research gap) mengenai faktorfaktor yang mempengaruhi pembelian kompulsif. Penelitian Dittmar (1996), Mowen dan Spears (1999), O'Guinn dan Faber (1989), Yurchisin dan Johnson (2004) dalam Johnson dan Attman (2009), Naomi dan Mayasari (2012), Quoquab, Yasin, dan Banu (2013) pada variabel materialism dan pembelian kompulsif 
menunjukkan bahwa materialism terbukti berpengaruh positif dan signifikan terhadap pembelian kompulsif. Berbeda dengan hasil-hasil penelitian tersebut, penelitian yang dilakukan oleh Jalees, Amen, dan Kazmi (2014) menunjukkan bahwa materialisme berpengaruh negatif tidak signifikan terhadap pembelian kompulsif.

Pengujian pada variabel financial literacy dan materialisme yang dilakukan oleh Utami (2011) menunjukkan bahwa financial literacy yang dimiliki seseorang dapat mengarahkan seseorang untuk menjadi pembeli yang cerdas sedangkan pada penelitian Nababan dan Sadalia (2013) menyimpulkan bahwa peningkatan praktek perilaku keuangan (financial behavior) tidak berbanding lurus dengan peningkatan pengetahuan keuangan (financial literacy).

Mengacu pada fenomena empiris serta perbedaan dari hasil-hasil penelitian terdahulu mendorong peneliti untuk merumuskan pertanyaan penelitian mengenai "Bagaiman menurunkan perilaku pembelian kompulsif?"

\section{TELAAH PUSTAKA DAN PENGEMBANGAN MODEL PENELITIAN}

\section{Perilaku Penggunaan Uang}

Menurut hasil penelitian yang dilakukanoleh Foster (2001), perilaku terhadap penggunaan uang sering diartikan sebagai motivasi terhadap uang yang dimilikinya. Uang yang berada di tangan seseorang akan mempunyai perlakuan berbeda antara satu dengan yang lain Dapat dikatakan bahwa perilaku terhadap penggunaan uang berarti akan dipergunakan untuk apakah uang yang dimiliki. Lebih lanjut penggunaan uang yang dimiliki oleh setiap individu dipengaruhi oleh berbagai hal seperti jenis kelamin yang melekat, pengalaman hidup, gaya hidup, rencana jangka panjang dan kebutuhan yang harus dipenuhi baik dalam jangka pendek maupun jangka panjang.

\section{Perilaku Konsumsi}

Menurut Swasta dan Handoko (1999), perilaku konsumsi merupakan tindakan yang langsung terlibat dalam mendapatkan, mengkonsumsi, dan menghabiskan produk dan jasa termasuk proses keputusan yang mendahului dan menyusuli tindakan ini.

\section{Perilaku Pembelian Kompulsif}

Perilaku pembelian kompulsif merupakan komponen perilaku negatif konsumen. Menurut O'Quinn dan Faber (1989) pembelian kompulsif merupakan salah satu bentuk konsumsi kompulsif yaitu pembelian yang kronik dan repetitif yang terjadi sebagai respon dari perasaan atau kejadian yang negatif. Dalam melakukan proses pembelian, motivasi pembeli kompulsif adalah sebagai sarana untuk meningkatkan harga dirinya dari pada untuk mengambil manfaat dan nilai-nilai ekonomis dari pembelian tersebut (O’Quinn dan Faber, 1989).

Konsep dasar perilaku pembelian kompulsif adalah konsumsi yang berlebihan pada suatu barang (Stones IV, 2001 dalam Shoham dan Brencic, 2003). Banyak peneliti yang mengkategorikan perilaku pembelian kompulsif sebagai gangguan terhadap kontrol pembelian impulsif (Black, dkk., 1998; Christenson, dkk, 1992; Faber, 1992; McElroy dkk, 1991; O’Guinn dan Faber, 1989; Schlosser, dkk, 1994 dalam Yang, 2006).

\section{Financial Literacy}

Pengetahuan yang berhubungan dengan keuangan dinamakan financial literacy. Financial literacy berkaitan dengan kompetensi seseorang untuk mengelola keuangan.

Financial Literacy menurut PISA (2012) adalah pengetahuan dan pemahaman atas konsep keuangan yang digunakan untuk membuat pilihan keuangan yang efektif, meningkatkan financial well being dari individu dan kelompok serta untuk berpartisipasi dalam kehidupan ekonomi. 
Financial literacy terjadi ketika individu memiliki sekumpulan keahlian dan kemampuan yang membuat orang tersebut mampu memanfaatkan sumber daya yang ada untuk mencapai tujuan.

\section{Materialisme}

Materialisme adalah salah satu komponen konsep diri yang penting adalah hubungan seseorang dengan dunia material. Materialisme mengacu pada orientasi konsumsi berbasis pencapaian kebahagiaan (Inglehart, 1981 dalam Hung, dkk, 2007). Pada suatu kondisi, harta diasumsikan menjadi posisi sentral dalam kehidupan seorang, dan merupakan sumber kepuasan dan ketidakpuasan (Belk, 1984 dalam Hung, dkk, 2007). Menurut Richin dan Dawson (1994 dalam Schiffman dan Kanuk, 2007), materialisme dibagi menjadi tiga dimensi yaitu: Dimensi pentingnya harta dalam hidup seseorang (acquisition centrallity) bertujuan untuk mengukur derajat keyakinan seseorang yang menganggap bahwa harta dan kepemilikan sangat penting dalam kehidupan seseorang. Dimensi kepemilikian merupakan ukuran kesuksesan hidup (possession defined success) untuk mengukur keyakinan seseorang tentang kesuksesan berdasarkan pada jumlah dan kualitas kepemilikannya, sedangkan dimensi kepemilikan dan harta benda merupakan sumber kebahagiaan (acquisition as the pursuit of happiness) untuk mengukur keyakinan apakah seseorang memandang kepemilikan dan harta merupakan hal yang penting untuk kesejahteraan dan kebahagiaan dalam hidup.

\section{Pengaruh Financial Literacy terhadap Materialisme}

Menurut Richins dan Dawson (1997) yang dimaksud dengan materialisme ialah sekumpulan keyakinan tentang pentingnya kepemilikan di dalam kehidupan seseorang. Keyakinan ini merupakan manifestasi dari tingkat dimana kepemilikan materi merupakan sumber utama dari kepuasan dan ketidakpuasan seseorang dalam hidupnya (Rindfleisch et al., 1997). Menurut Belk (1985) materialisme berhubungan erat dengan tiga dimensi yaitu: kepemilikan (possessiveness), ketidakdermawanan (nongenerosity) dan kecemburuan (invy). Sedangkan Richins dan Dawson (1997) menilai bahwa nilainilai material dihubungkan dengan kepercayaan diri yang rendah, ketidakpuasan dengan kehidupan, dan ketidakpuasan dengan penghasilan yang tinggi. Jadi materialisme merupakan keyakinan utama individu bahwa uang, kepemilikan, dan kekayaan dipertimbangkan sebagai sesuatu yang relatif tinggi dan menonjol dalam kehidupan seseorang dibandingkan dengan penerimaan diri, persahabatan serta rasa kemanusiaan.

Sedangkan financial literacy memiliki makna sebagai kemampuan untuk secara efektif mengevaluasi dan mengelola keuangan seseorang dalam rangka untuk membuat keputusan hemat untuk mencapai tujuan hidup dan mencapai kesejahteraan finansial. Melalui financial literacy yang baik diharapkan dapat menurunkan perilaku materialisme. Penelitian yang dilakukan oleh Utami (2011) menunjukkan bahwa financial literacy yang dimiliki seseorang dapat mengarahkan seseorang untuk menjadi pembeli yang cerdas.

Penelitian yang dilakukan oleh Nababan dan Sadalia (2013) menyimpulkan bahwa peningkatan praktek perilaku keuangan (financial behavior) tidak berbanding lurus dengan peningkatan pengetahuan keuangan (financial literacy).

Mengacu pada uraian di atas maka hipotesis yang dikembangkan dalam penelitian ini adalah:

\section{H1: Financial literacy berpengaruh negatif terhadap materialisme}

\section{Pengaruh Financial Literacy terhadap Perilaku Pembelian Kompulsif}

Salah satu kecerdasan yang harus dimiliki oleh manusia modern adalah kecerdasan finansial, yaitu kecerdasan dalam mengelola aset keuangan pribadi. 
Dengan menerapkan cara pengelolaan keuangan yang benar, maka seseorang diharapkan bisa mendapatkan manfaat yang maksimal dari uang yang dimilikinya. Dalam kehidupan pribadi seseorang, pada dasarnya sebuah keputusan keuangan yang diambil ada tiga: (1) berapa jumlah yang harus dikonsumsi tiap periode; (2) apakah ada kelebihan penghasilan dan bagaimana kelebihan tersebut diinvestasikan; dan (3) bagaimana mendanai konsumsi dan investasi tersebut. Dalam rangka mencapai kesejahteraan keuangan, seseorang perlu memiliki pengetahuan, sikap, dan implementasi keuangan pribadi yang sehat. Sejauh mana pengetahuan, sikap dan implementasi seseorang dalam mengelola keuangan, dikenal dengan literasi finansial.

Mahasiswa sebagai generasi muda tidak hanya akan menghadapi kompleksitas yang semakin meningkat dalam produk-produk keuangan, jasa, dan pasar, tetapi mereka lebih cenderung harus menanggung resiko keuangan di masa depan yang lebih dari orang tua mereka. Mahasiswa dihadapkan pada permasalahan apakah mereka secara finansial sudah siap untuk hidup mandiri, dan memulai sebuah keluarga. Chen dan Volpe (1998) dalam penelitiannya menemukan bahwa mahasiswa yang memiliki tingkat literasi finansial rendah cenderung berpendapat negatif tentang keuangan dan membuat keputusan yang salah. Dengan memiliki literasi finansial, mahasiswa mampu membuat keputusan untuk kehidupan mereka dan menerima tanggung jawab atas tindakan mereka sendiri.

Sina (2012) dalam publikasinya menyatakan bahwa untuk menciptakan nilai yang terkristal dalam perilaku dibutuhkan financial literacy karena pada prinsipnya financial literacy merupakan alat yang berguna untuk merubah perilaku dari tidak cerdas menjadi cerdas.

Peningkatan praktek perilaku keuangan (financial behavior) tidak berbanding lurus dengan peningkatan pengetahuan keuangan (financial literacy). Artinya, perilaku keuangan seseorang tidak selalu dipengaruhi oleh tingkat pengetahuan yang dimilikinya tetapi juga dipengaruhi oleh keberadaan faktor-faktor lain seperti faktor psikologis dan emosi.

Penelitian yang dilakukan oleh Imawati, Susilaningsih dan Ivada (2013) pada variabel financial literacy dan perilaku konsumtif menunjukkan bahwa financial literacy terbukti berpengaruh negatif signifikan terhadap perilaku konsumtif. Artinya, seseorang yang memiliki financial literacy yang baik akan memiliki kemampuan untuk membatasi diri terhadap pembelian barang-barang yang tidak memiliki manfaat yang besar dan akan lebih mementingkan untuk menyimpan uangnya dalam rangka memperoleh kesejahteraan yang lebih baik.

Mengacu pada uraian di atas maka hipotesis yang dikembangkan dalam penelitian ini adalah:

\section{H2: Financial literacy berpengaruh negatif terhadap perilaku pembelian kompulsif}

\section{Pengaruh Materialisme terhadap Perilaku Pembelian Kompulsif}

Konsep nilai materialisme dan pembelian kompulsif perlu dipelajari karena menimbulkan berbagai konsekuensi negatif terhadap kesejahteraan psikologis (well - being) individu seperti: menurunnya tingkat kepuasan hidup (Richins dan Dawson, 1992 dalam Burroughs dan Rindfleisch, 2002), menurunnya tingkat kebahagiaan (Belk,1985 dalam Burroughs dalam Rindfleisch, 2002), serta meningkatnya tingkat depresi (Kasser dan Ryan, 1993 dalam Burroughs dan Rindfleisch, 2002). Materialisme juga dapat mempengaruhi perilaku konsumsi, penggunaan kartu kredit dan berhutang. Seseorang dengan derajat materalisme yang tinggi akan diikuti pula oleh pengeluaran dan keinginan berhutang yang tinggi (Watson, 1998 dalam Yang, 2006).

Konsumen dengan tendensi materialistik yang kuat akan menggunakan fashion 
untuk membuat suatu kesan, hal ini akan lebih mengarah pada keterlibatan yang lebih tinggi. Semakin seseorang menganggap suatu kepemilikan sebagai suatu yang berharga maka orang tersebut semakin materialistik, demikian juga sebaliknya (Browne dan Kaldenberg, 1997 dalam O'Cass, 2004).

Beberapa penelitian sebelumnya menemukan bahwa seseorang yang materialistis cenderung untuk menjadi pembeli yang kompulsif (Dittmar, 1996; Mowen dan Spears, 1999; O'Guinn dan Faber, 1989; Yurchisin dan Johnson, 2004 dalam Johnson dan Attman, 2009). Sebagai tambahan, para peneliti juga menemukan bahwa seseorang yang materialis memiliki keterlibatan yang tinggi pada produk pakaian (Browne dan Kaldenberg, 1997; Yurchisin dan Johnson, 2004 dalam Johnson dan Attman, 2009). Oleh karenanya, sangatlah beralasan bahwa seseorang dengan nilai materialistik yang tinggi akan memiliki tingkat pembelian kompulsif pakaian yang tinggi. Demikian pula dengan penelitian yang dilakukan oleh Quoquab, Yasin, dan Banu (2013) pada variabel materialisme dan pembelian kompulsif menunjukkan bahwa materialisme terbukti berpengaruh positif dan signifikan terhadap pembelian kompulsif.

Penelitian Naomi dan Mayasari (2012) melakukan pengujian terhadap variabel materialisme terhadap perilaku pembelian kompulsif. Dimana variabel materialisme yang diteliti tersebut dibedakan menjadi tiga, yaitu materialisme kesuksesan, materialisme sentralitas, dan materialisme kebahagiaan. Dari ketiga kategori materialisme tersebut, hanya dua kategori materialisme, yaitu materialisme sentralitas dan materialisme kebahagiaan yang terbukti berpengaruh positif dan signifikan terhadap perilaku pembelian kompulsif sedangkan materialisme kesuksesan tidak mempengaruhi perilaku pembelian kompulsif.

Berbeda dengan hasil-hasil penelitian lainnya, penelitian yang dilakukan oleh
Jalees, Amen, dan Kazmi (2014) menunjukkan bahwa materialisme berpengaruh negatif tidak signifikan terhadap pembelian kompulsif.

Mengacu pada uraian di atas maka hipotesis yang dikembangkan dalam penelitian ini adalah:

\section{H3: Materialisme berpengaruh positif terhadap perilaku pembelian kompulsif}

\section{METODE PENELITIAN}

\section{Definisi Operasional dan Pengukuran Variabel Penelitian}

Variabel financial literacy adalah tingkat pengetahuan dan pemahaman yang dimiliki oleh responden mengenai konsep keuangan yang digunakan untuk membuat pilihan keuangan yang efektif, meningkatkan financial well being dari individu dan kelompok serta untuk berpartisipasi dalam kehidupan ekonomi. Pengukuran pada variabel financial literacy dilakukan dengan menggunakan indikator-indikator sebagai berikut (Nababan dan Sadalia, 2013):

1. Pengetahuan dasar tentang keuangan pribadi (X1);

2. Pengetahuan dasar tentang manajemen uang (X2);

3. Pengetahuan mengenai kredit atau hutang (X3);

4. Pengetahuan mengenai tabungan atau investasi (X4);

5. Pengetahuan tentang pengelolaan resiko (X5).

Materialisme yang diteliti dalam penelitian ini adalah suatu tendesi atau kecenderungan responden penelitian mencapai kebahagiaan melalui kepemilikan benda tertentu disebut materialisme. Pengukuran variabel materialisme diukur melalui indikator-indikator berikut ini (Schiffman dan Kanuk, 2007):

1. Mengutamakan kepemilikan (X6);

2. Egois atau terpusat pada diri sendiri (X7);

3. Senantiasi mencari gaya hidup yang penuh dengan kepemilikan (X8); 
4. Selalu mengharapkan kepemilikan yang lebih tinggi agar mendapatkan kebahagian yang lebih besar (X9).

Variabel perilaku pembelian kompulsif didefinisikan sebagai suatu kegiatan pembelian yang kronik dan repetitif yang hanya didorong lebih pada keinginan untuk meningkatkan harga dirinya dari pada untuk mengambil manfaat dan nilai-nilai ekonomis dari pembelian tersebut. Pengukuran variabel perilaku kompulsif diukur melalui beberapa indikator sebagai berikut (Mayasari dan Naomi, 2008):

1. Tidak ditujukan untuk memenuhi kebutuhan utama (X10);

2. Membeli secara terus menerus (X11);

3. Tidak mempertimbangkan dampak pembelian (X12);

4. Mempengaruhi harmonisasi (keluarga atau dengan lingkungan sosial) (X13);

5. Individu tidak memiliki kontrol atas perilaku pembelian (X14);

6. Pembelian lebih ditujukan untuk menghilangkan kekhawatiran atau ketakutan (X15);

7. Sebagai bentuk kompensasi misalnya karena kurang perhatian keluarga (X16).

\section{Populasi}

Populasi dalam penelitian ini adalah Taruna Tingkat III Politeknik Ilmu Pelayaran (PIP) Semarang yang berjumlah 401.

\section{Sampel}

Sampel adalah sebagian dari populasi yang memiliki karakteristik yang relatif sama dan dianggap bisa mewakili populasi (Singarimbun, 1991). Penentuan jumlah sampel untuk analisis Structural Equation Modeling menggunakan rumus (Ferdinand, 2005) jumlah indikator x 5 sampai 10. Karena dalam penelitian ini terdapat 16 indikator, maka jumlah sampel yang digunakan adalah 80-160 responden. Selanjutnya Hair, dkk dalam Ferdinand (2005) menyatakan bahwa ukuran yang sampel sesuai untuk SEM adalah antara 100 - 200 sampel. Dengan mengacu pada pendapat Hair maka jumlah sampel yang digunakan dalam penelitian adalah 160 responden.

\section{Metode Pengumpulan Data}

Untuk mengumpulkan data penelitian, kuesioner dipilih sebagai metode pengumpulan data dalam penelitian ini. Tipe pertanyaan dalam kuesioner adalah pertanyaan tertutup. Pada pertanyaan tertutup, responden diminta untuk membuat pilihan diantara serangkaian alternatif yang diberikan oleh peneliti (Sekaran, 2006). Skala data jawaban responden atas pertanyaan penelitian dengan menggunakan Agree-Disagree Scale yang menghasilkan jawaban sangat tidak setuju - jawaban sangat setuju dalam rentang nilai $1 \mathrm{~s} / \mathrm{d} 10$ (Ferdinand, 2006).

\section{Teknik Analisis}

Untuk menguji model dan hubungan yang dikembangkan dalam penelitian ini diperlukan suatu teknik analisis. Adapun teknik analisis yang digunakan dalam penelitian ini adalah Structural Equation Modeling (SEM) yang dioperasikan melalui progam AMOS.

\section{HASIL PENELITIAN DAN PEMBAHASAN}

\section{Pengujian Asumsi SEM}

Setelah melakukan analisis measurement model melalui analisis faktor konfirmatori dan dilihat bahwa masing-masing indikator dapat digunakan untuk mendefinisikan sebuah konstruk laten, maka tahap yang kedua adalah melakukan pengujian asumsi SEM. Berikut ini dijelaskan hasil evaluasi asumsi dalam pemodelan SEM sebagai berikut :

\section{Evaluasi Normalitas Data}

Asumsi ini merupakan syarat dalam penggunaan SEM. Tujuan dari evaluasi ini adalah untuk mengidentifikasikasi normalitas sebaran data dengan menggunakan nilai pada tabel normalitas yang dihasilkan dari program 
Amos terhadap skewness value (nilai Z) yang setara dengan Critical Ratio (CR) pada level signifikansi $0,01(1 \%)$ yaitu sebesar $\pm 2,58$. Jika nilai Critical Ratio yang dihasilkan dari setiap variabel penelitian lebih kecil dari 2,58 maka distribusi data adalah normal. Tabel 1 menunjukkan hasil uji normalitas data.

Tabel 1

Hasil Uji Normalitas Data

\begin{tabular}{|l|rrrrrr|}
\hline Variable & min & $\max$ & skew & c.r. & kurtosis & c.r. \\
\hline X14 & 1,000 & 10,000 &,- 720 & $-3,720$ &,- 340 &,- 878 \\
X13 & 1,000 & 10,000 &,- 604 & $-3,119$ &,- 419 & $-1,083$ \\
X12 & 1,000 & 10,000 &,- 601 & $-3,102$ &,- 059 &,- 151 \\
X11 & 1,000 & 10,000 &,- 645 & $-3,330$ &,- 329 &,- 851 \\
X10 & 1,000 & 10,000 &,- 954 & $-4,926$ &, 814 & 2,101 \\
X9 & 1,000 & 10,000 &,- 266 & $-1,374$ &,- 439 & $-1,132$ \\
X8 & 1,000 & 10,000 &,- 261 & $-1,348$ &,- 849 & $-2,192$ \\
X7 & 1,000 & 10,000 &,- 563 & $-2,908$ &,- 206 &,- 531 \\
X6 & 1,000 & 10,000 &,- 127 &,- 658 &,- 570 & $-1,471$ \\
X5 & 1,000 & 10,000 &, 237 & 1,224 &,- 906 & $-2,339$ \\
X4 & 1,000 & 10,000 &, 303 & 1,567 &,- 748 & $-1,931$ \\
X3 & 1,000 & 10,000 &, 443 & 2,288 &,- 128 &,- 330 \\
X2 & 1,000 & 10,000 &, 180 &, 932 &,- 625 & $-1,614$ \\
X1 & 1,000 & 10,000 &, 285 & 1,474 &,- 723 & $-1,866$ \\
Multivariate & & & & & 6,955 & 2,078 \\
\hline
\end{tabular}

Sumber : Data primer yang diolah, 2016

Dari hasil perhitungan normalitas univariate yang disajikan di atas ditunjukkan bahwa nilai CR multivariate tidak lebih besar dari 2,58 yaitu sebesar 2,078 sehingga dapat disimpulkan bahwa distribusi data penelitian adalah normal.

\section{Evaluasi atas Outliers}

Outliers adalah observasi yang muncul dengan nilai-nilai ekstrim secara multivariate yaitu muncul karena kombinasi kharakteristik unik yang dimilikinya dan terlihat sangat jauh berbeda dari variabel-variabel lainnya.
Deteksi multivatiate outliers dilakukan dengan membandingkan tabel output hasil komputasi SEM yang ditunjukkan melalui nilai Mahalanobis distance pada level signifikansi $(\mathrm{p}<$ $0,001)$ terhadap nilai Chi-Square $\left(\chi^{2}\right)$ pada degree of freedom (df) sebesar jumlah indikator. Jika di observasi memiliki nilai Mahalanobis distance > $\chi^{2}$, maka diidentifikasi sebagai multivariate outliers. Hasil uji multivariate outliers secara lengkap ditunjukkan pada print out Structural Equation Modelling. Tabel 2 hanya menampilkan 5 observasi teratas hasil pengujian multivariate outliers.

Tabel 2

Pengujian Univariate Outliers

\begin{tabular}{|r|rrr|}
\hline Observation number & Mahalanobis d-squared & p1 & p2 \\
\hline 128 & 32,260 &, 004 &, 446 \\
49 & 31,763 &, 004 &, 153 \\
45 & 27,441 &, 017 &, 507 \\
105 & 26,589 &, 022 &, 461 \\
39 & 26,339 &, 023 &, 322 \\
\hline
\end{tabular}

Sumber : Data primer yang diolah, 2016 
Hasil uji terhadap ke-16 indikator variabel penelitian menghasilkan nilai $\chi^{2}$ $(16 ; 0,001)$ adalah sebesar 39.252 (dilihat pada tabel Chi-Square). Sedangkan dalam tabel di atas terlihat bahwa nilai Mahalanobis Disctance maksimal adalah 32.260. Oleh karena nilai Mahalanobis Disctance maksimal $<$ nilai $\chi^{2}$ tabel, maka dapat disimpulkan bahwa data dalam penelitian ini memenuhi asumsi bebas multivariate outliers.

\section{Evaluasi atas Multicollinearity dan} Singularity

Pengujian asumsi ini dapat diidentifikasikan melalui nilai determinant of sample covariance matrix. Jika nilai determinan lebih besar atau jauh dari 0 (nol) maka dapat diindikasikan tidak terdapat multicollinearity dan singularity. Hasil dari pengolahan menunjukkan bahwa nilai determinand of sample covariance matrix sebesar 37532226,824 yang lebih besar dari nol. Ini berarti bahwa keseluruhan data yang digunakan pada penelitian ini layak digunakan karena tidak terdapat multicollinearity dan singularity.

\section{AnalisisResidual}

Dalam pengujian dengan SEM nilai residualnya haruslah kecil atau mendekati nol dan distribusi frekuensi dari kovarians residual haruslah bersifat simetrik. Jika suatu model memiliki nilai kovarians residual yang tinggi $(>2,58)$ maka sebuah modifikasi perlu dipertimbangkan dengan landasan teori yang kuat.

Dari hasil analisis statistik yang dilakukan dalam penelitian ini, tidak ditemukan nilai standardized residual kovarians yang lebih dari 2,58 sehingga dapat dikatakan bahwa syarat residual terpenuhi.

\section{Pengujian Model Penelitian}

Setelah dilakukan evaluasi terhadap asumsi-asumsi SEM, selanjutnya adalah evaluasi terhadap kesesuaian model yang diajukan dalam penelitian ini dengan berbagai kriteria goodness-of-fit yang telah dikemukakan pada bagian sebelumnya. Dari model yang diajukan dan dihubungkan dengan data akan diketahui bagaimana hubungan kausal antara financial literacy, materialisme dan perilaku pembelian kompulsif. Hasil pengolahan terhadap model yang diajukan diuraikan berikut ini.

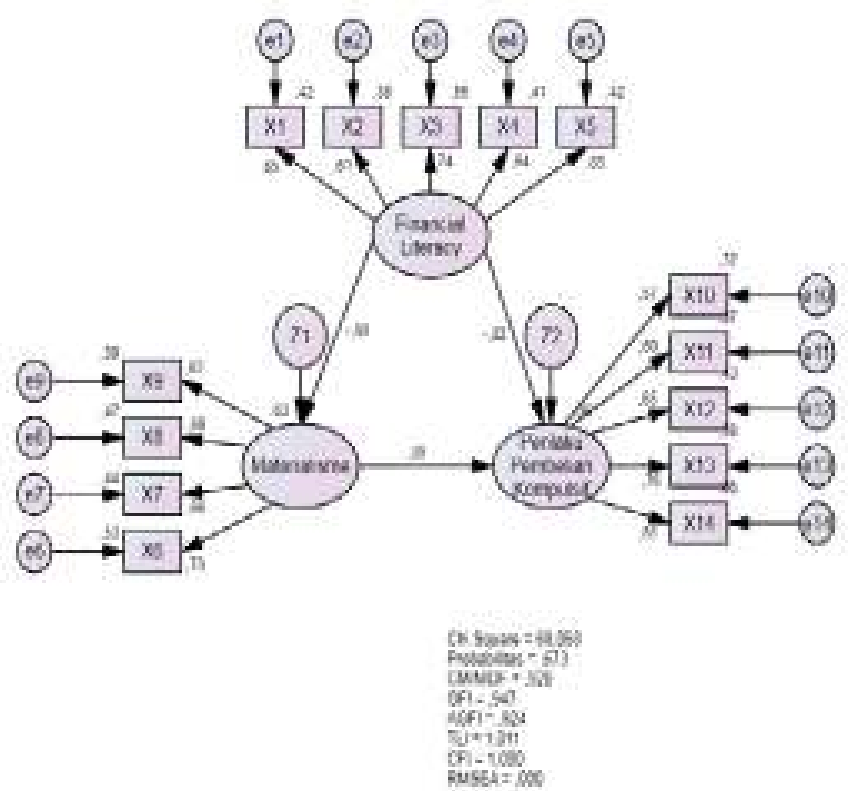

Gambar Hasil Pengujian SEM pada Model Penelitian

Sumber : Data primer yang diolah, 2016 
Untuk mengetahui ketepatan model dengan data penelitian, maka dilakukan pengujian goodness-of-fit. Indeks hasil pengujian dibandingkan dengan nilai kritis untuk menentukan baik atau tidaknya model tersebut, yang diringkas dalam tabel berikut ini.

Tabel 3

Penilaian Goodness of Fit Model Penelitian

\begin{tabular}{|l|c|c|c|}
\hline Goodness of Fit Indeks & Cut off Value & Hasil & Evaluasi Model \\
\hline Chi-Square $(\mathrm{df}=74)$ & Kecil $(<95.081)$ & 68.058 & Baik \\
\hline Probability & $\geq 0,05$ & 0.673 & Baik \\
\hline GFI & $\geq 0,90$ & 0.947 & Baik \\
\hline AGFI & $\geq 0,90$ & 0.924 & Baik \\
\hline CMIN/DF & $\leq 2,00$ & 0.920 & Baik \\
\hline TLI & $\geq 0,95$ & 1.011 & Baik \\
\hline CFI & $\geq 0,95$ & 1.000 & Baik \\
\hline RMSEA & $\leq 0,08$ & 0.000 & Baik \\
\hline
\end{tabular}

Sumber : Data primer yang diolah, 2016

Berdasarkan hasil pengujian kelayakan model yang disajikan dalam Tabel 3 di atas menunjukkan bahwa secara keseluruhan kriteria pengujian dalam kategori baik atau memenuhi kriteria penilaian yang dipersyaratkan. Pada uji Chi-Square, sebuah model akan dianggap baik jika hasilnya menunjukkan nilai ChiSquarehitung yang lebih kecil dari nilai ChiSquare tabel. Semakin Chi Square hitung yang lebih kecil dari nilai Chi Square tabel menunjukkan bahwa semakin baik model tersebut berarti tidak ada perbedaan antara estimasi populasi dengan sampel yang diuji. Model penelitian ini menunjukkan bahwa nilai $C h i$ Square hitung adalah 68.058, sedangkan nilai kritis/tabel Chi Square dengan df $=74$ adalah 95.081. Ini berarti bahwa model penelitian ini tidak berbeda dengan populasi yang diestimasi/model dianggap baik (diterima) karena Chi-Square dalam penelitian ini lebih kecil dari nilai kritis/tabelnya. Komponen yang lain probability (P), RMSEA, CMIN/DF, GFI, AGFI, TLI, CFI juga berada dalam rentang nilai yang diharapkan sehingga dapat disimpulkan bahwa keseluruhan model baik.

\section{Pengujian Hipotesis}

Setelah dilakukan uji asumsi SEM dan kesesuaian model (model fit) maka selanjutnya dilakukan pengujian hipotesis hubungan kausalitas variabel penelitian. Hasil uji hipotesis hubungan antara variabel ditunjukkan dari nilai RegressionWeight pada kolom CR (identik dengan t-hitung) yang di bandingkan dengan nilai kritisnya (identik dengan t-tabel). Nilai kritis untuk level signifikansi 0,05 (5\%) adalah 1,998 (lihat pada t-tabel), sedangkan nilai kritis untuk level signifikansi $0,1(10 \%)$ adalah 1,66 (lihat pada t-tabel). Jika nilai CR > nilai kritis, maka hipotesa penelitian akan diterima, sebaliknya jika nilai $\mathrm{CR}<$ nilai kritis, maka penelitian ditolak. Nilai regression weight hubungan antara variabel ditunjukkan dalam tabel 4. 
Analisis Pengaruh Financial Literacy Terhadap Materialisme Dan Perilaku Membelanjakan Uang (Studi Pada Taruna Politeknik Ilmu Pelayaran (PIP) Semarang)

Desy Aryani

Tabel 4

Regression Weight

\begin{tabular}{|c|c|c|c|c|c|c|c|}
\hline & & & $\begin{array}{r}\text { Std } \\
\text { Estimate }\end{array}$ & $\begin{array}{r}\text { Estimat } \\
\mathrm{e}\end{array}$ & S.E. & C.R. & $\mathrm{P}$ \\
\hline Materialisme & $<---$ & $\begin{array}{l}\text { Financial_ } \\
\text { Literacy }\end{array}$ &,- 795 &,- 872 &, 142 & $-6,140$ & $* * *$ \\
\hline $\begin{array}{l}\text { Perilaku_Pembelian } \\
\text { Kompulsif }\end{array}$ & $<---$ & Materialisme &,- 390 &,- 286 & , 164 & $-1,737$ & ,082 \\
\hline $\begin{array}{l}\text { Perilaku_Pembelian } \\
\text { Kompulsif }\end{array}$ & $<---$ & $\begin{array}{l}\text { Financial_ } \\
\text { Literacy }\end{array}$ &,- 320 &,- 257 & ,179 & $-1,435$ & ,151 \\
\hline
\end{tabular}

Berdasarkan data dalam tabel 4 maka dapat disajikan hasil pengujian terhadap hipotesis-hipotesis penelitian :

\section{Pengujian Pengaruh Financial Literacy - Materialisme}

Parameter estimasi untuk pengujian pengaruh financial literacy terhadap materialisme menunjukkan nilai $\mathrm{CR}$ sebesar -6,140 dengan probabilitas sebesar 0,000. Oleh karena nilai CR yang dihasilkan dari perhitungan lebih besar dari nilai kritis pada level signifikansi $0,05(5 \%)$ yaitu 1,998 serta nilai probabilitas yang dihasilkan $(0,000)$ adalah $<0,05$ maka dapat disimpulkan bahwa variabel financial literacy secara statistik terbukti berpengaruh negatif dan signifikan terhadap materialisme.

\section{Pengujian Pengaruh Financial Literacy-Perilaku Pembelian Kompulsif}

Parameter estimasi untuk pengujian pengaruh financial literacy terhadap perilaku pembelian kompulsif menunjukkan nilai $\mathrm{CR}$ sebesar-1,435 dengan probabilitas sebesar 0,151. Oleh karena nilai $\mathrm{CR}$ yang dihasilkan dari perhitungan lebih kecil dari nilai kritis pada level signifikansi $0,05(5 \%)$ yaitu 1,998 serta nilai probabilitas yang dihasilkan $(0,151)$ adalah $>0,05$ maka dapat disimpulkan bahwa variabel financial literacy secara statistik terbukti berpengaruh negatif dan tidak signifikan terhadap perilaku pembelian kompulsif.

\section{Pengujian Pengaruh Materialisme - Perilaku Pembelian Kompulsif}

Parameter estimasi untuk pengujian pengaruh materialisme terhadap perilaku pembelian kompulsif menunjukkan nilai CR sebesar -1,737 dengan probabilitas sebesar 0,082. Oleh karena nilai CR yang dihasilkan dari perhitungan lebih kecil dari nilai kritis pada level signifikansi 0,05 (5\%) yaitu 1,998 serta nilai probabilitas yang dihasilkan $(0,082)$ adalah $>0,05$ maka dapat disimpulkan bahwa variabel materialisme secara statistik terbukti berpengaruh negatif dan tidak signifikan terhadap perilaku pembelian kompulsif.

Berdasarkan hasil pengujian model yang dikembangkan dalam penelitian ini menunjukkan bahwa financial literacy terbukti berpengaruh negatif signifikan terhadap materialisme, artinya ketika financial literacy yang dimiliki oleh mahasiswa meningkat maka hal tersebut akan menekan atau menurunkan perilaku materialisme mahasiswa.

\section{PENUTUP}

\section{A. Kesimpulan}

1. Pengujian yang dilakukan pada variabel financial literacy dan materialisme menunjukkan bahwa secara statistik financial literacy 
terbukti berpengaruh negatif signifikan terhadap materialisme. Hasil pengujian ini menunjukkan bahwa jika financial literacy yang dimiliki semakin baik maka hal ini akan menurunkan sikap materialisme.

2. Pengujian yang dilakukan pada variabel materialisme dan perilaku pembelian kompulsif menunjukkan bahwa secara statistik materialisme terbukti berpengaruh negatif tidak signifikan terhadap perilaku pembelian kompulsif. Hasil pengujian ini menunjukkan bahwa sikap materialisme yang dimiliki tidak serta merta menyebabkan munculnya perilaku pembelian kompulsif.

3. Pengujian yang dilakukan pada variabel financial literacy dan perilaku pembelian kompulsif menunjukkan bahwa secara statistik financial literacy terbukti berpengaruh negatif tidak signifikan terhadap perilaku pembelian kompulsif. Hasil pengujian ini menunjukkan bahwa financial literacy yang dimiliki tidak serta merta menyebabkan munculnya perilaku pembelian kompulsif.

\section{B. Saran}

Berpijak pada keterbatasan penelitian yang ditemukan pada studi ini maka pendekatan variabel lain yang diduga dapat mempengaruhi perilaku pembelian kompulsif adalah personality traits dan income.

\section{DAFTAR PUSTAKA}

Afrizal. 2012. Perilaku Konsumtif Picu Kriminalitas. Haluan. Diperoleh 5 Februari 2014, dari www.haluanmedia.com/padang

Belk, Russel W. 1985. Materialism: Trait aspects of living in the material world. Journal of Consumer Research, 12 (December), 265-280

Black, D. W. 1998. A Review of Compulsive Buying Disorder, Journal of Psychiatry, 6 (1), 14-18

Browne, B dan D. Kaldenberg. 1997. Conseptualizing Self-Monitoring: Links to Materialism and Product Involvement, Journal of Consumer Marketing, 14(1), 31-44

Burroughs, J. E., dan Aric Rindfleisch. 2002. Materialism and WellBeing:A Conflicting Values Perspective, Journal of Consumer Research, (29),348-370

Chen, H dan R.P Volpe. 1998. An Analysis of Personal Financial Literacy Among College Student, Financial Services Review, 7(2), 107-128

Christenson, Gary A et al. 1992. Compulsive Buying: Descriptive Characteristics and Psychiatric Comorbidity. Journal of Clinical Psychiatry, 55, 5-11

Dittmar, H. 2005. Compulsive Buying-A Growing Concern? An Examination of Gender, Age, and Endorsement of Materialistic Values As Predictors. British Journal of Psychology, Vol.96, pp. 467-491

Faber, R.J. and T.C O'Guinn. 1992. Compulsive Buying: A Phenomenological Exploration. Journal of Consumer Research, Vol. 16, pp. 147-157

Faber, RJ. 1992. Money Changes Everythings. American Behavioral Scientist, 35, 809-819

Gilarso, T. 1992. Pengantar Ekonomi Makro. Yogyakarta : Kanisius

Huston, S. J. 2010. Measuring Financial Literacy, Journal of Consumer Affairs, Volume 44 Issue 2

Imawati, Indah., Susilaningsih, Elvia Ivada. 2013. Pengaruh Financial Literacy 
Desy Aryani

terhadap Perilaku Konsumtif Remaja pada Program IPS SMA Negeri 1 Surakarta Tahun Ajaran 2012/2013, Jupe UNS, 2 (1), 48-58

Jalees, Tariq, Ume Amen, Qurat ul Ain Kazmi. 2014. A Structural Approach on Compulsive Buying Behavior. Institute of Business Administration Karachi

Kwak, H., G. M Zinkhan, and M. R Crask. 2003. Diagnostic Screener for Compulsive Buying: Applicationsto the USA and South Korea, Vol. 37, No. 1, pp. 161-169

Lina dan H. F Rosyid. 1997. Perilaku Konsumtif Berdasarkan Locus of Control pada Remaja Putri,Jurnal Pemikiran dan Penelitian Psikologi, No.4 Tahun XI, halaman 5-13

Mayasari, I dan Naomi, P. 2008. Faktor Faktor yang Mempengaruhi Siswa SMA dalam Perilaku Pembelian Kompulsif: Perspektif Psikologi. Jurnal Manajemen dan Bisnis, Vol. 3 , No. 2

Mowen, John C dan Nancy Spears. 1999. Compulsive Buying Among College Students: A Hierarchical Model Approach. Journal of Consumer Psychology, 8 (4), 407-430

Nababan, Darman dan Isfenti Sadelia. 2013. Analisis Personal Financial
Literacy dan Financial Behavior. Mahasiswa Strata I Fakultas Ekonomi Universitas Sumatera Utara

Naomi, Prima dan Iin Mayasari. 2012. Faktor-Faktor yang Mempengaruhi Siswa SMA Dalam Perilaku Pembelian Kompulsif: Perspektif Psikologi

O'Guinn, Thomas C dan Ronald J Faber. 1989. Compulsive Buying: A Phenomenological Exploration, Journal of Consumer Research, 16 (September), 147-157

PISA. 2012. Financial Literacy Framework. Australia

Quoquab, Farzana., Norjana Mohd Yasin dan Shamsiah Banu. 2013. Compulsive Buying Behavior Among Young Malaysian Consumer. World Review of Business Research, 3 (2)

Richins, Marsha L dan Scott Dawson. 1992. A Consumer Values Orientation For Materialism And Its Measurement: Scale Development And Validation, Journal of Consumer Research, 19 (December), 303-316

Sina, Peter Garlans. 2012. Analisis Literasi Ekonomi. Jurnal Economia, 8 (2), 135-143 